\title{
Caffeic Acid Inhibits RANKL and TNF $\alpha$-induced Osteoclastogenesis by Targeting TAK1-p44/42 MAPK
}

\author{
Ferry Sandra ${ }^{1, *}$, Jennifer Putri², Hilary Limen², Blanca Sarizta ${ }^{2}$ \\ ${ }^{1}$ Department of Biochemistry and Molecular Biology, Division of Oral Biology, Faculty of Dentistry, Universitas Trisakti, Jl. Kyai Tapa No. 260, \\ Jakarta, Indonesia \\ ${ }^{2}$ Faculty of Dentistry, Universitas Trisakti, Jl. Kyai Tapa No. 260, Jakarta, Indonesia \\ ${ }^{*}$ Corresponding author. E-mail: ferry @ trisakti.ac.id
}

Received date: Nov 23, 2021; Revised date: Nov 29, 2021; Accepted date: Nov 30, 2021

\section{Abstract}

B ACKGROUND: The potential of the caffeic acid in other important Receptor Activator Nuclear Factor $\kappa \mathrm{B}$ Ligand (RANKL)-Tumor Necrosis Factor (TNF) $\alpha$-induced osteoclastogenic signaling pathways has not been known. Therefore, the current study was conducted to explore as well as to understand the inhibition potential of caffeic acid.

METHODS: RAW264.7 cells were cultured, treated with caffeic acid, RANKL and TNF $\alpha$. Tartrate Resistant Acid Phosphatase (TRAP) staining was performed to detect TRAP $^{+}$osteoclast-like polynuclear cells. To detect the activity of p44/42 Mitogen Activated Protein Kinase (MAPK), Akt, and Transforming Growth Factor- $\beta$-activated Kinase (TAK)1, the phosphorylated forms of the proteins were investigated with the immunoblotting assay.
RESULTS: Pre-treatment of caffeic acid inhibited the RANKL and TNF $\alpha$-induced differentiation of RAW264.7 cells into $\mathrm{TRAP}^{+}$osteoclast-like polynuclear cells. RANKL and TNF $\alpha$ induced phosphorylation of p44/42 MAPK at Thr202/Tyr204, phosphorylation of Akt at both Ser473 and Thr308 and phosphorylation of TAK1 at Ser412. Pretreatment with caffeic acid prior to the RANKL and TNF $\alpha$ induction, inhibited the phosphorylation of MAPK, and TAK1, but not Akt.

CONCLUSION: Caffeic acid might regulate the RANKLTNF $\alpha$-induced osteoclastogenic pathway in RAW264.7 by targeting TAK1, which later activation of p44/42 MAPK was abolished.

KEYWORDS: caffeic acid, osteoclastogenesis, p44/42, Erk1/2, Akt, TAK1, RAW264.7

Indones Biomed J. 2021; 13(4): 433-7

\section{Introduction}

Bone remodeling process is a complex mechanism, influenced by osteoclast and osteoblast. Osteoclast is a major bone resorbing factor derived from hematopoietic stem cells, induced by various cytokines such as Receptor Activator Nuclear Factor $\mathrm{\kappa B}$ Ligand (RANKL), Tumor Necrosis Factor (TNF)- $\alpha$, Macrophage Colony Stimulating Factor (M-CSF), Interleukin (IL)-1 $\alpha$ and IL-6.(1,2) The bindings of RANKL to RANK and TNF to TNF receptor further induces intracellular signaling pathways, including Tumor Necrosis Factor Receptor (TNFR)-associated
Factor 6 (TRAF6) (3), Mitogen Activated Protein Kinase (MAPK) family (4-6) and Nuclear Factor $\kappa B$ (NFkB) (7). Activated MAPK family consists of p44/42 MAPK (4), p38 MAPK $(4,5)$, and c-Jun N-Terminal Kinase (JNK) or Stress Activated Protein Kinase (SAPK) (6).

The inhibition of osteoclastogenesis can be achieved by using inhibitors related to the upregulated signals. The 6877002 (inhibitor of TRAF6) (8), U0126 and PD98059 (inhibitors of p44/42 MAPK) (9), SB203580 (inhibitor of p38) (10), SP600125 (inhibitor of JNK/SAPK) (11) and JSH 23 (NFKB inhibitor) (12) have been reported to inhibit osteoclastogenesis. Besides the molecules mentioned above, there are numerous efforts in finding potential inhibitors, 
including the approach in herbal extract. Some herbal extracts have shown their potencies in inhibiting osteoclastogenesis through different pathways. $(3-7,13)$

Amongst the herbal extracts, caffeic acid, often found in berries and Japanese sweet potato has been studied for its potential to protect human cells from several diseases including cancer and bone resorption.(3,5-7,14) Caffeic acid activated the Caspases, further inducing osteosarcoma cells into apoptosis.(15,16) Meanwhile, in bone resorption, caffeic acid has a potential in inhibiting RANKL-TNFainduced osteoclastogenesis through TRAF6, p38 MAPK, JNK/SAPK, Nuclear Factor of Activated T-cells cytoplasmic 1 (NFATc1), and NFKB.(3,5-7) However, potential of the caffeic acid in other important osteoclastogenic signaling pathways, such as p44/42 MAPK (17) and Akt (18), have not been known. These pathways should be explored as well to understand inhibition potential of caffeic acid. In addition, the TRAF6 was reported to be not inhibited by caffeic acid. Therefore, another potential downstream of the RANKL \& TNF $\alpha$ signaling pathway should be explored. Amongst them, Transforming Growth Factor- $\beta$-activated Kinase 1 (TAK1) (18-20), which was reported to regulate the development and function of osteoclasts was explored.

\section{Methods}

\section{Cell Culture}

RAW264.7 cells were cultured in 96-well plates or 6-well plates with $\alpha$-MEM (GIBCO, Grand Island, NY), 10\% Fetal Bovine Serum (Sigma-Aldrich, St. Louis, MO) and penicillin-streptomycin, in a $37^{\circ} \mathrm{C}$ humidified incubator with $5 \% \mathrm{CO}_{2}$.

\section{Osteoclastogenesis}

Pre-treatment of $10 \mu \mathrm{g} / \mathrm{mL}$ caffeic acid (Sigma-Aldrich) was conducted for 2 hours prior to the treatment of 20 $\mathrm{ng} / \mathrm{mL}$ RANKL (PeproTech, London, UK) and $1 \mathrm{ng} / \mathrm{mL}$ TNFa (Sigma-Aldrich). After 3 days, Tartrate Resistant Acid Phosphatase (TRAP) staining using Leukocyte Acid Phosphatase Kit (Sigma-Aldrich) was performed. TRAP+ polynuclear cells (PNCs) were documented under an inverted microscope.

\section{Immunoblotting Assay}

Treated cells were harvested and incubated with lysis buffer containing $10 \mathrm{mM}$ Tris buffer ( $\mathrm{pH} 7.4), 150 \mathrm{mM}$ $\mathrm{NaCl}, 1 \%$ Triton-X100 and $100 \mu \mathrm{L}$ protease inhibitor cocktail (Sigma-Aldrich). The proteins in the samples were separated by sodium dodecyl sulfate (SDS)-polyacrylamide gel electrophoresis and transferred to a nitrocellulose membrane (Bio-Rad, Richmond, CA, USA). After blocking with 5\% skim milk in phosphate buffer saline (PBS) $(\mathrm{pH}$ 7.4), the membrane was probed with 1:1000 diluted rabbit polyclonal anti-phospho-p44/42 MAPK (Thr202/ Tyr204) (Cell Signaling Technology, Beverly, MA, USA), anti-p44/42 MAPK (Cell Signaling Technology), antiphospho-Akt (Ser473) (Cell Signaling Technology), antiphospho-Akt (Thr308) (Cell Signaling Technology), antiAkt (Cell Signaling Technology), anti-phospho-TAK1 (Ser412) (Cell Signaling Technology) or anti-TAK1 (Cell Signaling Technology) antibody. The secondary antibody was 1:2000 diluted horseradish peroxidase-conjugated donkey anti-rabbit antibody (Cell Signaling Technology). The bound antibodies were visualized using Immun-Star HRP Chemiluminescent Kit (Bio-Rad). All visualized bands were captured using Alliance 4.7 (UVItech, Cambridge, UK) and quantified using UVIband software (UVItech).

\section{Results}

RANKL and TNF $\alpha$-induced Osteoclastogenesis was Inhibited by Caffeic Acid

Induction of $20 \mathrm{ng} / \mathrm{mL}$ RANKL and $1 \mathrm{ng} / \mathrm{mL} \mathrm{TNF} \alpha$ successfully differentiated RAW264.7 cells into TRAP $^{+}$ osteoclast-like PNCs (Figure 1B). Pre-treatment of 10 $\mu \mathrm{g} / \mathrm{mL}$ caffeic acid could inhibit the RANKL and TNF $\alpha$ induced differentiation of RAW264.7 cells into TRAP $^{+}$ osteoclast-like PNCs (Figure 1C).

RANKL and TNFa-induced Phosphorylation of p44/42 MAPK at Thr202/Tyr204 was Inhibited by Caffeic Acid Treatment of $20 \mathrm{ng} / \mathrm{mL}$ RANKL and $1 \mathrm{ng} / \mathrm{mL}$ TNF $\alpha$ for 0.2 , 1,6 and 12 hours induced phosphorylation of p44/42 MAPK markedly at Thr202/Tyr204, especially phosphorylation of p44 (Figure 2). The phosphorylation of p44/42 MAPK was observed at 0.2 hour treatment. The highest phosphorylation level of p44/42 MAPK was observed at 1 hour treatment. The phosphorylation level was then decreased gradually. Pre-treatment of caffeic acid inhibited the phosphorylation of p44/42 MAPK induced by RANKL and TNF $\alpha$ (Figure 2).

RANKL and TNF $\alpha$-induced Phosphorylation of Akt at Ser473 and Thr308 was Not Inhibited by Caffeic Acid Treatment of $20 \mathrm{ng} / \mathrm{mL}$ RANKL and $1 \mathrm{ng} / \mathrm{mL}$ TNF $\alpha$ for 0.2 , 1, 6 and 12 hours induced phosphorylation of Akt markedly at both Ser473 and Thr308 (Figure 3). The phosphorylation 

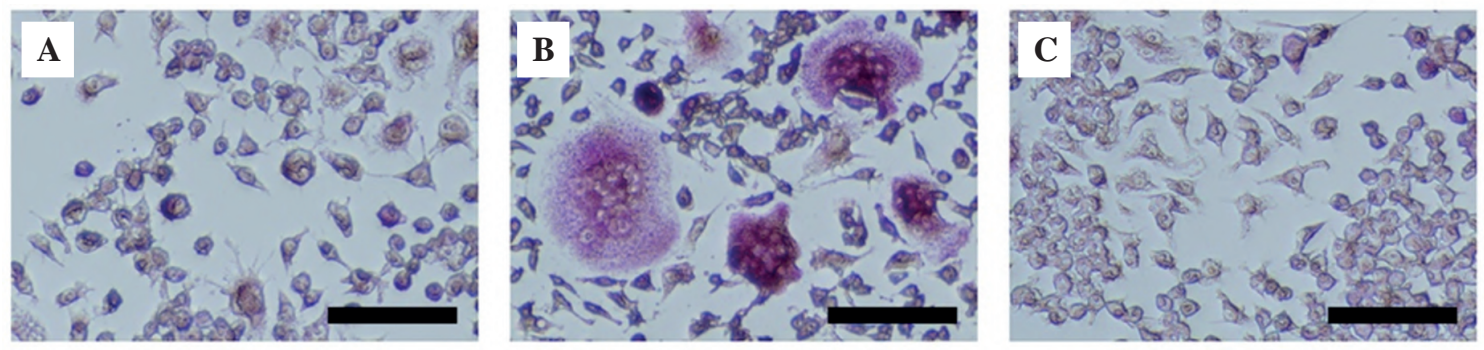

Figure 1. RANKL and TNF $\alpha$-induced osteoclastogenesis in RAW264.7 cells were inhibited by caffeic acid. RAW264.7 cells were pre-treated with/without $10 \mu \mathrm{g} / \mathrm{mL}$ caffeic acid for 2 hours and treated with/without $20 \mathrm{ng} / \mathrm{mL}$ RANKL and $1 \mathrm{ng} / \mathrm{mL}$ TNF $\alpha$ for 3 days. A: Untreated RAW264.7 cells; B: RAW264.7 cells were treated with RANKL and TNF $;$; : RAW264.7 cells were pre-treated with caffeic acid then treated with RANKL and TNF $\alpha$. Black bar: $100 \mu \mathrm{m}$.

of Akt at both Ser 473 and Thr308 were observed at 0.2 hour treatment. The phosphorylation levels of Akt at both Ser 473 and Thr308 were almost the same up to 12 hours treatment. Pre-treatment of caffeic acid did not inhibit the phosphorylation of Akt at both Ser473 and Thr308.

\section{RANKL and TNF $\alpha$-induced Phosphorylation of TAK1 at Ser412 was Inhibited by Caffeic Acid}

Treatment of $20 \mathrm{ng} / \mathrm{mL}$ RANKL and $1 \mathrm{ng} / \mathrm{mL} \mathrm{TNF} \alpha$ for 0.2 , 1,6 and 12 hours induced phosphorylation of TAK 1 at Ser 412 markedly. The phosphorylation of TAK1 was markedly increased at 0.2 hour treatment. The phosphorylation level was then decreased gradually. Pre-treatment of caffeic acid inhibited the phosphorylation of TAK1 induced by RANKL and TNF $\alpha$ (Figure 4).

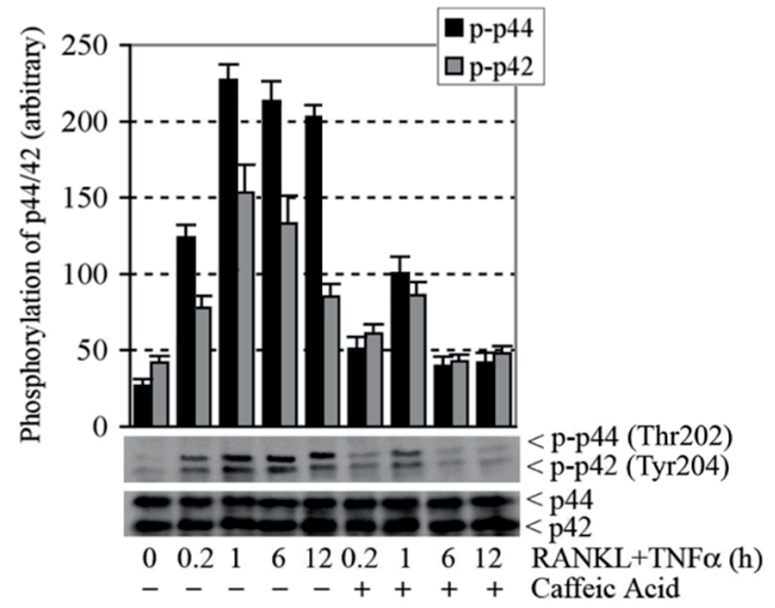

Figure 2. RANKL and TNF $\alpha$-induced phosphorylation of p44/42 in RAW264.7 cells was inhibited by caffeic acid. RAW264.7 cells were pre-treated with/without $10 \mu \mathrm{g} / \mathrm{mL}$ caffeic acid for 2 hours and treated with $20 \mathrm{ng} / \mathrm{mL}$ RANKL and $1 \mathrm{ng} / \mathrm{mL}$ TNF $\alpha$ for 0, 0.2, 1, 6 and 12 hours. Cells were lysed and subjected to immunoblotting assay using anti-p44/42 or anti-p-p44/42 antibody. Data represent a typical result from 3 independent experiments. p-p44: phosphorylated p44; p-p42: phosphorylated $\mathrm{p} 42$.

\section{Discussion}

In the current study, RANKL and TNFa induced phosphorylation of p44/42 MAPK markedly, especially phosphorylation of p44 MAPK or also known as Extracellular signal-regulated kinase (Erk)1. Erk1 has been known to positively regulate osteoclast development and bone resorptive activity.(21) Impaired osteoclast differentiation and reduced number of osteoclast progenitors in the bone marrow of $\mathrm{Erkl}^{-/}$mice has been reported. (21) In our current results, the RANKL-TNF $\alpha$-induced phosphorylation of p44/42 MAPK or phosphorylation of Erk1/2 was inhibited by caffeic acid, which was shown to inhibit osteoclastogenesis. Therefore, p44/42 MAPK could

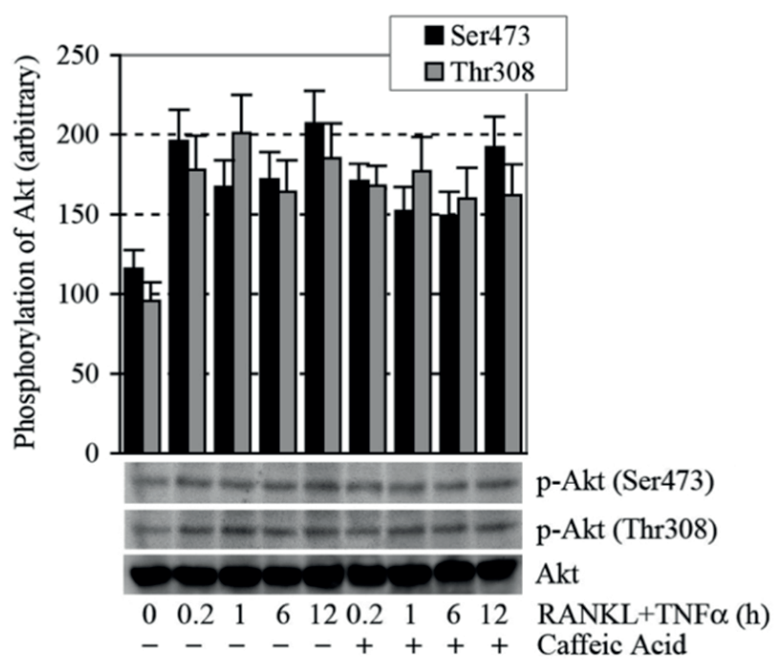

Figure 3. RANKL and TNF $\alpha$-induced phosphorylation of Akt in RAW264.7 cells was not inhibited by caffeic acid. RAW264.7 cells were pre-treated with/without $10 \mu \mathrm{g} / \mathrm{mL}$ caffeic acid for 2 hours and treated with $20 \mathrm{ng} / \mathrm{mL}$ of RANKL and $1 \mathrm{ng} / \mathrm{mL}$ of TNF $\alpha$ for $0,0.2,1,6$ and 12 hours. Cells were lysed and subjected to immunoblotting assay using anti-Akt, anti-p-Akt at Ser473 or antip-Akt at Thr308 antibody. Data represent a typical result from 3 independent experiments. p-Akt: phosphorylated Akt. 


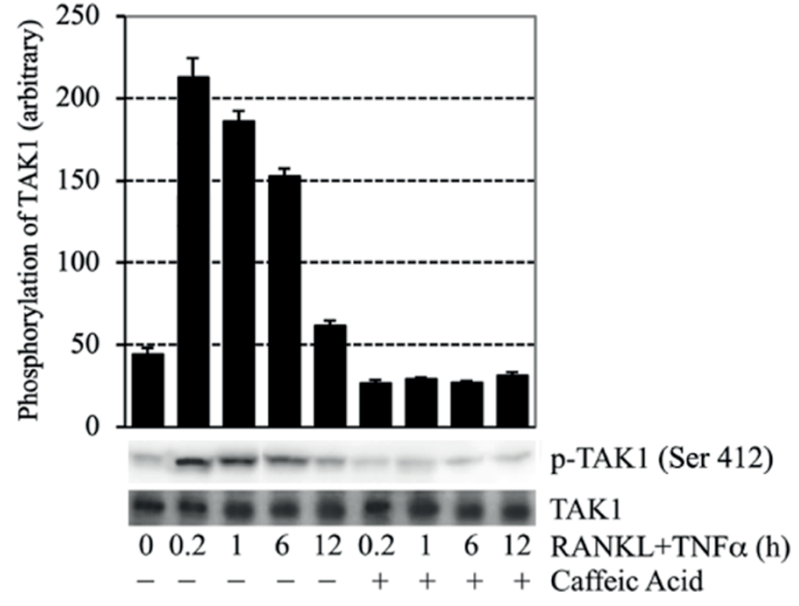

Figure 4. RANKL and TNF $\alpha$-induced phosphorylation of TAK1 was inhibited by caffeic acid. RAW264.7 cells were pretreated with/without $10 \mu \mathrm{g} / \mathrm{mL}$ caffeic acid for 2 hours and treated with $20 \mathrm{ng} / \mathrm{mL}$ RANKL and $1 \mathrm{ng} / \mathrm{mL}$ TNF $\alpha$ for $0,0.2,1,6$ and 12 hours. Cells were lysed and subjected to immunoblotting assay using anti-TAK1 or anti-p-TAK1 antibody. Data represent a typical result from 3 independent experiments. p-TAK1: phosphorylated TAK1.

be suggested to play important role in the osteoclastogenic pathway induced by RANKL-TNF $\alpha$ and caffeic acid could regulate the phosphorylation.

With the induction of RANKL-TNF $\alpha$, phosphorylation of Akt was also increased at both Ser473 and Thr308. Moreover the role of Akt in osteoclast differentiation has been well reported.(18) However, unlike phosphorylation of p44/42 MAPK, the RANKL-TNF $\alpha$-induced phosphorylation of Akt at both Ser473 and Thr308 was not inhibited by caffeic acid. These results suggested caffeic acid might inhibit selectively the signals in the osteoclastogenic pathway. Therefore, several $\mathrm{TRAP}^{+}$osteoclast-like PNCs could be observed in the group treated with caffeic acid prior to RANKL-TNF $\alpha$, as reported previously.(7)

TAK1, an important factor in RANKL-TNF $\alpha$ induced osteoclast differentiation, was shown to be highly phosphorylated in our RAW264.7 cells as well.(20) The phosphorylation was observed in an early period of time, about $0.2 \mathrm{~h}$ or $12 \mathrm{~min}$. The phosphorylation of TAK1 was inhibited by caffeic acid. This result suggested that caffeic acid might regulate the RANKL-TNF $\alpha$-induced osteoclastogenic pathway in RAW264.7 by targeting TAK1. This result is in accordance to our previous report showing that TRAF6 was not inhibited by caffeic acid, since the caffeic acid inhibited TAK1, the downstream of TRAF6. (22) By inhibiting phosphorylation of TAK1, therefore all p44/42 MAPK, p38 MAPK (5), JNK/SAPK (6) and
NFKB (7) were inhibited. Caffeic acid's inhibition in TAK1 complexes including TAK1-binding protein (TAB)1, TAB2 and other related molecules should be further investigated.

\section{Conclusion}

Taken together, caffeic acid might regulate the RANKLTNF $\alpha$-induced osteoclastogenic pathway in RAW264.7 by targeting TAK1, which later activation of p44/42 MAPK was abolished.

\section{Authors Contribution}

FS was involved in concepting and planning the research. JP, HL and BS performed the data acquisition/collection. FS calculated the experimental data and performed the analysis. JP, HL and BS drafted the manuscript and designed the figures. FS revised the manuscript and figures, also aided in interpreting the results. All authors took parts in giving critical revision of the manuscript.

\section{References}

1. Toh K, Kukita T, Wu Z, Kukita A, Sandra F, Tang QY, et al. Possible involvement of MIP- $1 \alpha$ in the recruitment of osteoclast progenitors to the distal tibia in rats with adjuvant-induced arthritis. Lab Invest. 2004; 84: 1092-102.

2. Ketherin, Sandra F. Osteoclastogenesis in periodontitis: signaling pathway, synthetic and natural inhibitors. Mol Cell Biomed Sci. 2018; 2: 11-8.

3. Sandra F, Kukita T, Muta T, Iijima T. Caffeic acid inhibited receptor activator of nuclear factor kappaB ligand (RANKL)-tumor necrosis factor (TNF) alpha-TNF receptor associated factor (TRAF) 6 induced osteoclastogenesis pathway. Indones Biomed J. 2013; 5: 173-8.

4. Chawalitpong S, Sornkaew N, Suksamrarn A, Palaga T. Diarylheptanoid from Curcuma comosa Roxb. suppresses RANKLinduced osteoclast differentiation by decreasing NFATc1 and c-Fos expression via MAPK pathway. Eur J Pharmacol. 2016; 788: 351-9.

5. Sandra F, Ketherin K. Caffeic Acid Inhibits RANKL and TNF- $\alpha-$ induced phosphorylation of p38 mitogen-activated protein kinase in RAW-D cells. Indones Biomed J. 2018; 10: 140-3.

6. Sandra F, Briskila J, Ketherin. RANKL and TNF-a-induced JNK/ SAPK osteoclastogenic signaling pathway was inhibited by caffeic acid in RAW-D cells. Indones J Cancer Chemoprevent. 2018; 9: 63-7.

7. Sandra F, Kukita T, Tang QY, Iijima T. Caffeic acid inhibits NFкB activation of osteoclastogenesis signaling pathway. Indones Biomed J. 2011; 3: 216-22.

8. Bishop RT, Marino S, Carrasco G, Li B, Allen RJ, Sparatore A, et al. Combined administration of a small-molecule inhibitor of 
TRAF6 and docetaxel reduces breast cancer skeletal metastasis and osteolysis. Cancer Lett. 2020; 488: 27-39.

9. Makeudom A, Supanchart C, Montreekachon P, Khongkhunthian S, Sastraruji T, Krisanaprakornkit J, et al. The antimicrobial peptide, human $\beta$-defensin- 1 , potentiates in vitro osteoclastogenesis via activation of the $\mathrm{p} 44 / 42$ mitogen-activated protein kinases. Peptides. 2017; 95: 33-9.

10. Matsumoto M, Sudo T, Saito T, Osada H, Tsujimoto M. Involvement of p38 mitogen-activated protein kinase signaling pathway in osteoclastogenesis mediated by receptor activator of NF-kappa B ligand (RANKL). J Biol Chem. 2000; 275: 31155-61.

11. Yamanaka Y, Clohisy JCF, Ito H, Matsuno T, Abu-Amer Y. Blockade of JNK and NFAT pathways attenuates orthopedic particlestimulated osteoclastogenesis of human osteoclast precursors and murine calvarial osteolysis. J Orthop Res. 2013; 31: 67-72.

12. Ren LR, Wang $\mathrm{H}, \mathrm{He} X Q$, Song MG, Chen XQ, Xu YQ. Staphylococcus aureus protein A induces osteoclastogenesis via the NF-אB signaling pathway. Mol Med Rep. 2017; 16: 6020-8.

13. Meng J, Zhang W, Wang C, Zhang W, Zhou C, Jiang G, et al. Catalpol suppresses osteoclastogenesis and attenuates osteoclast-derived bone resorption by modulating PTEN activity. Biochem Pharmacol. 2020; 171: 113715. doi: 10.1016/j.bcp.2019.113715.

14. Tang QY, Kukita T, Ushijima Y, Kukita A, Nagata K, Sandra F, et al. Regulation of osteoclastogenesis by Simon extracts composed of caffeic acid and related compounds: successful suppression of bone destruction accompanied with adjuvant-induced arthritis in rats. Histochem Cell Biol. 2006; 125: 215-25.

15. Sandra F, Sidharta MA. Caffeic acid induced apoptosis in MG63 osteosarcoma cells through activation of caspases. Mol Cell Biomed Sci. 2017; 1: 28-33.

16. Sandra F, Hudono KF, Putri AA, Putri CAP. Caspase inhibitor diminishes caffeic acid-induced apoptosis in osteosarcoma. Indones Biomed J. 2017; 9: 160-4.

17. Kim HH, Chung WJ, Lee SW, Chung PJ, You JW, Kwon HJ, et al. Association of sustained ERK activity with integrin beta3 induction during receptor activator of nuclear factor kappaB ligand (RANKL)-directed osteoclast differentiation. Exp Cell Res. 2003; 289: 368-377.

18. Moon JB, Kim JH, Kim K, Youn BU, Ko A, Lee SY, et al. Akt induces osteoclast differentiation through regulating the GSK3 $\beta /$ NFATc1 signaling cascade. J Immunol. 2012; 188: 163-9.

19. Mizukami J, Takaesu G, Akatsuka H, Sakurai H, Ninomiya-Tsuji J, Matsumoto K, et al. Receptor activator of NF- $\mathrm{kB}$ Ligand (RANKL) activates TAK1 mitogen-activated protein kinase kinase kinase through a signaling complex containing RANK, TAB2, and TRAF6. Mol Cell Biol. 2002; 22: 992-1000.

20. Kobayashi Y, Mizoguchi T, Take I, Kurihara S, Udagawa N, Takahashi N. Prostaglandin E2 enhances osteoclastic differentiation of precursor cells through protein kinase A-dependent phosphorylation of TAK1. J Biol Chem. 2005; 280: 11395-403.

21. He Y, Staser K, Rhodes SD, Liu Y, Wu X, Park SJ, et al. Erk1 positively regulates osteoclast differentiation and bone resorptive activity. PLoS One. 2011; 6: e24780. doi: 10.1371/journal.pone.0024780.

22. Park JH, Lee NK, Lee SY. Current Understanding of RANK Signaling in Osteoclast Differentiation and Maturation. Mol Cells. 2017; 40: 706-13. 